DOI: 10.5604/01.3001.0012.5279

\title{
ELECTRICAL RESISTANCE TOMOGRAPH FOR DISTRIBUTED MEASUREMENTS FOR FLOOD EMBANKMENT
}

\author{
Tomasz Rymarczyk $^{1,2}$, Paweł Tchórzewski ${ }^{1}$, Przemyslaw Adamkiewicz ${ }^{1}$, Jan Sikora $^{1}$ \\ ${ }^{1}$ Research and Development Center, Netrix S.A., Lublin, ${ }^{2}$ University of Economics and Innovation in Lublin
}

Abstract. In this paper the terrain electrical resistance tomograph was presented. Its aim is to verify the repeatability of test results by eliminating laboratory equipment, and to validate the use of simple and cheap electronics to the structure of the ERT. Electrical resistance tomography, which is based on measuring potential difference, can be used to calculate conductivity

Keywords: electrical resistance tomography; sensors; measurements

\section{ELEKTRYCZNY TOMOGRAF REZYSTANCYJNY DO POMIARÓW ROZPROSZONYCH DLA WALÓW PRZECIWPOWODZIOWYCH}

Streszczenie. W niniejszym artykule przedstawiono konstrukcję tomografu rezystancyjnego. Jego celem jest weryfikacja powtarzalności wyników badań poprzez wyeliminowanie sprzętu laboratoryjnego oraz potwierdzenie zastosowania prostej i taniej elektroniki do struktury ERT. Do obliczenia przewodnictwa można wykorzystać elektryczna tomografię rezystancyjna, która opiera się na pomiarze różnicy potencjałów

Slowa kluczowe: tomografia rezystancyjna, sensory, pomiary

\section{Introduction}

Electrical tomography (ET) is known that the inverse problem is nonlinear and highly ill-posed [5,10-12]. Electrical Resistance tomography (ERT) is a geophysical technique in which DC electrical current is injected into the ground between one pair of electrodes and the voltage is measured between another pair. ERT involves placing electrodes on the examined object. In this work, there was created a device after achieving good research results of measurements. Its aim was to verify the repeatability of test results by eliminating laboratory equipment, and to validate the use of simple and cheap electronics. The ERT equipment consists of some separated modules: current generator, measure block, multiplexer and controller. The data acquisition system collects the measured voltage from electrode and then the data is processed. The problem is the low level of measured values which should be measured quite accurately and in a very short time. ERT involves placing electrodes on the examined object $[1,2]$. Different methods can be used to reconstruct the image in the optimization process $[3,4,6-8]$.

\section{Measurement system}

The ERT solution should make ERT measurements for reconstruction of resistive distribution at big areas (tens of meters) with of conducting media. The ERT equipment consists of some separated modules: current generator, measure block, multiplexer and controller. These modules should adapt to high voltages (about $250 \mathrm{~V}$ ) and high currents (about $3 \mathrm{~A}$ ). There should be possibility to connect more than one multiplexer to this system. The designed modules should be supervised and served by a single controller. A schematic diagram of the system is presented in Fig. 1.

The ERT solution should make ERT measurements for reconstruction of resistive distribution at big areas (tens of meters) with of conducting media $[9,10]$. The ERT equipment consists of some separated modules: current generator, measure block, multiplexer and controller (Fig. 2 and Fig. 3). These modules should adapt to high voltages (about $250 \mathrm{~V}$ ) and high currents (about $3 \mathrm{~A}$ ). There should be possibility to connect more than one multiplexer to this system. The designed modules should be supervised and served by a single controller. The signal power amplifier as a finished device is also located in the $2 \mathrm{U}$ housing.

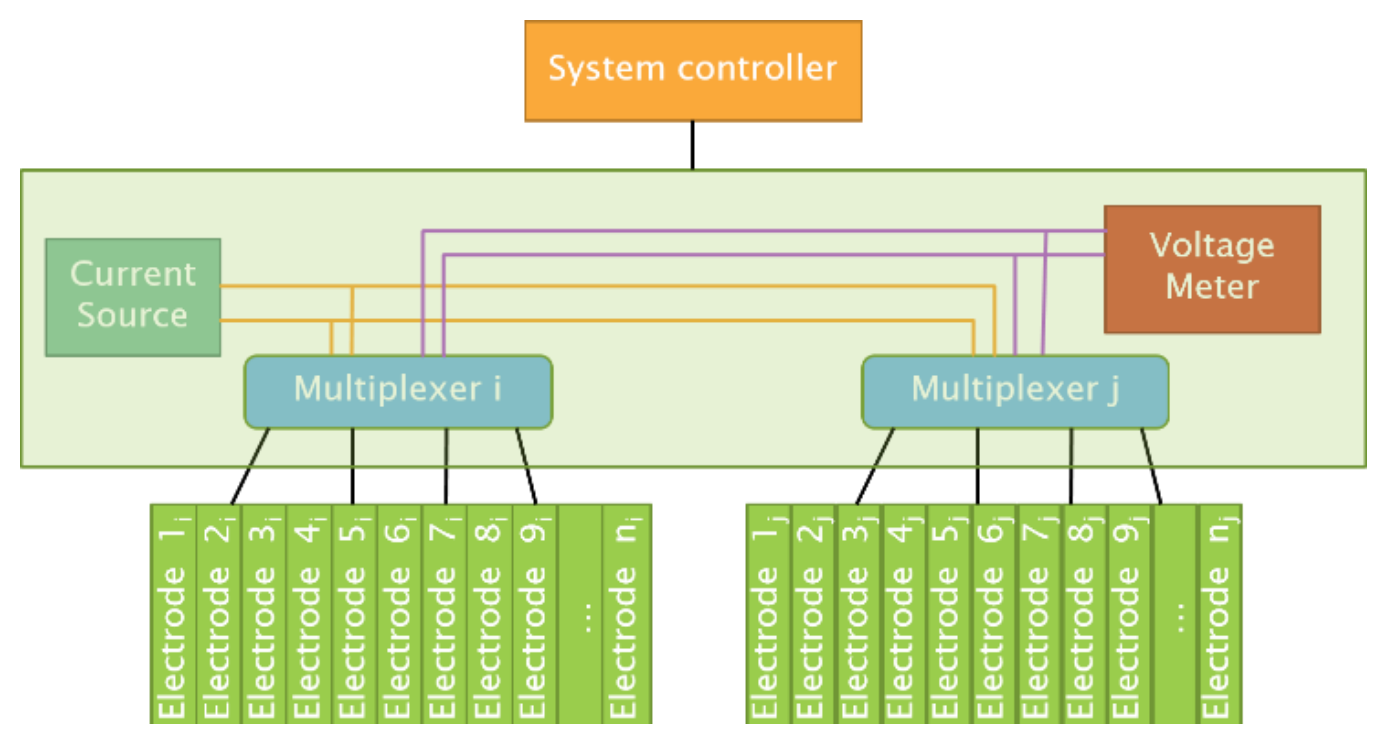

Fig. 1. The ERT measurement system schematic diagram 

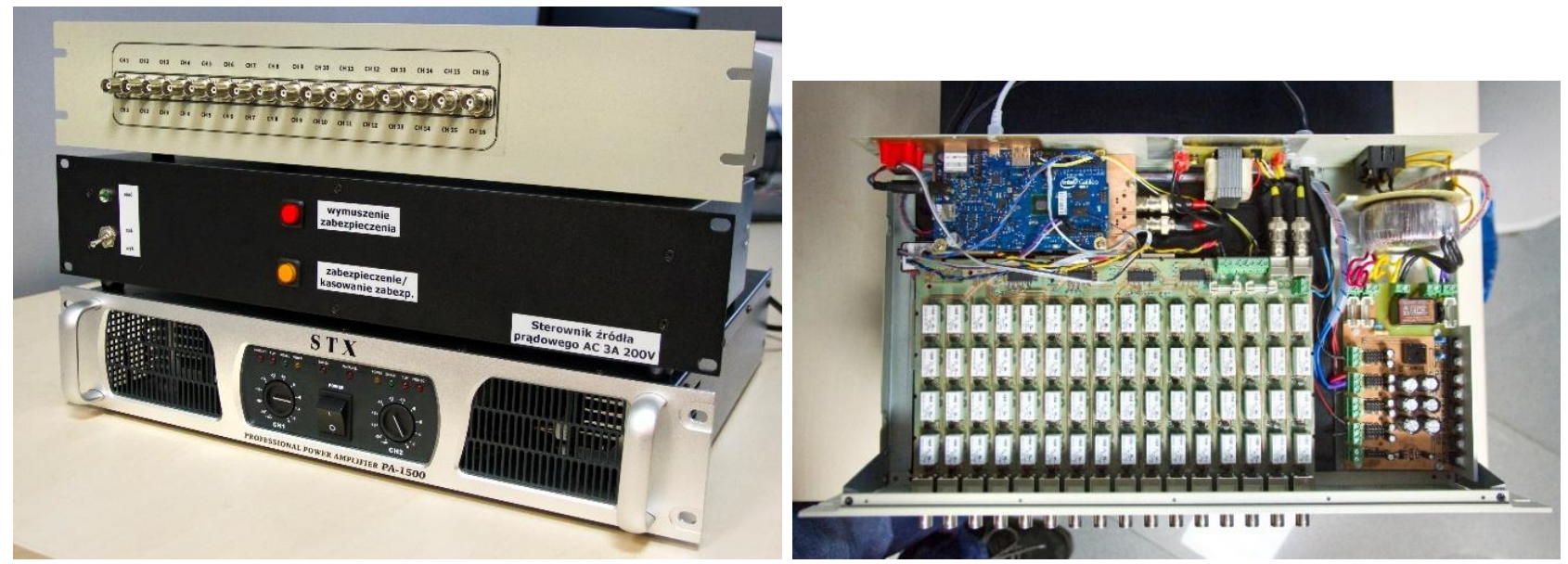

Fig. 2. ERT device

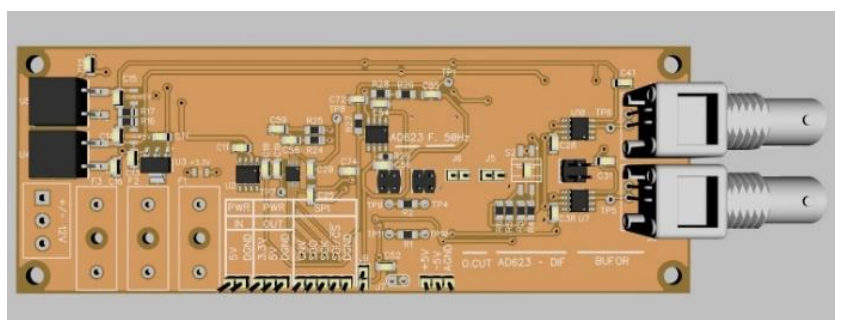

Fig. 3. ADC module

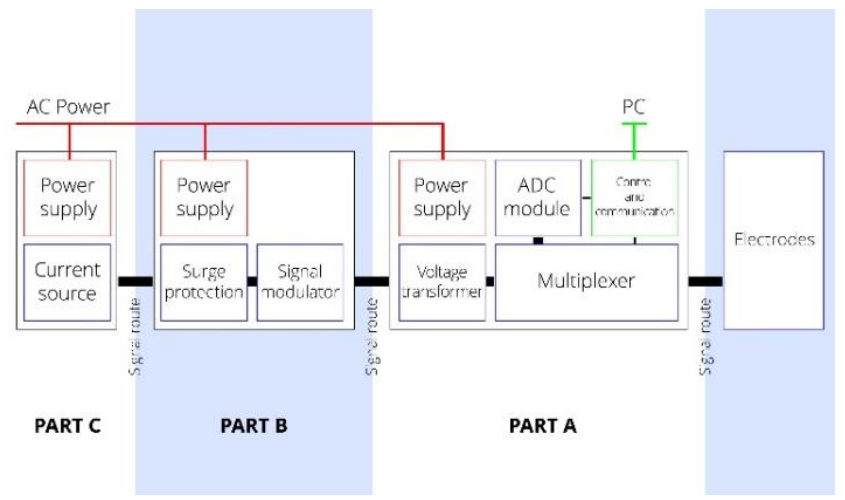

Fig. 4. System scheme

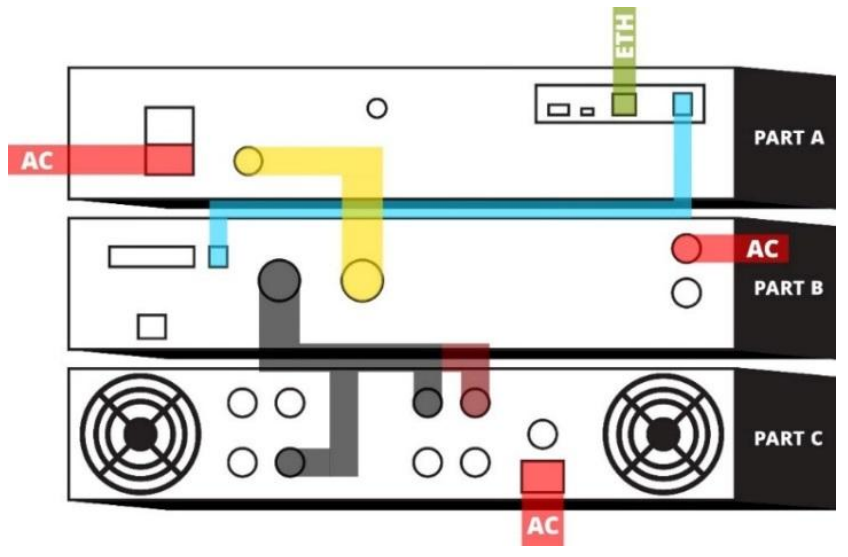

Fig. 5. Connections between back panels of scanner's central unit
The device consists of 3 central unit modules (Fig. 5) and a set of measuring electrodes. External connection diagram is presented in Fig. 4.

Part $\mathrm{A}$ is equipped with multiplexer as well as with control and communication circuitry. On its back-panel IEC 60320 power socket with on/off switch, excitation signal cable connected to part $\mathrm{B}$, and a voltage transformer's knob can be found as well as following sockets:

- USB ("USB Host", not used),

- microUSB ("USB Client", for optional direct communication with a computer),

- Ethernet ("LAN", for control of the device and for obtaining measurement data),

- RJ-11 ("UART", for communication with part B).

Front panel is equipped with $16 \mathrm{BNC}$ sockets for measuring electrodes.

Part B (AC current source controller) consists of excitation signal modulator and surge protection unit. Front panel is equipped with lever power switch, status diode and 2 back-lit buttons for manual toggling of surge protection. Back panel consists of following sockets:

- USB-B ("USB 2.0", diagnostic, for firmware update),

- DB25 ("control", not used),

- RJ-11 ("UART", for communication with part A),

- Plug-in 7-pin ("to an audio amplifier", connected to part C),

- Plug-in 3-pin ("galvanically isolated output", output for part A),

- $\quad$ fuse mount ("230V $50 \mathrm{~Hz} 15 \mathrm{VA} ")$.

Additionally, there's a fixed AC power cable.

Part C (current source) has been enclosed in audio amplifier chassis. Back-lit power switch and two unused knobs can be found on the front panel. On the back one there are multiple sockets, mostly unused with the exception of:

- female XLR (lower "Bridge input", used for connection with part B),

- two red clamp sockets ("Bridge +"; connecting with part B, red cable with left one and black cable with right one accordingly),

- $\quad$ IEC 60320 power socket ("AC in"),

- Fuse mount ("Main fuse"). 


\section{Communication protocol}

The basics of communication were made using MQTT v. 3.1.1 protocol. Broker's IP address and local area network settings are fixed in firmware of the central unit. Its uncompiled form is attached to this manual. The device uses MQTT default port 1883 . Every command addressed to the device may receive and realized in monitoring mode. In standby mode device monitors communication, the whole time. During operation it switches to monitoring mode for a brief moment between measuring cycles.

Every successfully received command is confirmed with a reply published most commonly in the same topic. After performing starting sequence and establishing network connection the device acquires time information from wwv.nist.gov. Next, it tries to connect to MQTT broker and in case of success it subscribes identified topics. It also uses topics NX02json (returns the measurement results there) and NX02status (returns device status and last will message) for publication. After subscribing the topics tomography scanner turns into standby mode. It is needed to select key parameters or the device will return the error message in topic NX02status, for example: "Measurement method not chosen". If broker maintains settings as a retained type messages the device will behave accordingly without any assist. In case of unsuccessful connection tomography scanner restarts its network, service and tries again. It is possible to obtain detailed error information with the USB serial port (mini-USB cable).

After performing the whole measurement cycle tomography scanner publishes JSON formatted data frame in NX02json topic according to following pattern:

\{,time”: ,aa”, ,dev_id”:"NXbbbbbVcccc”, ,electrodes":”16”, „,samples":"dd”, ,frequency":"ee”, ,method":"f",

„Wggg”:"hh.hhh", ..., „Wggg”:"'hh.hhhh"\}

where:

aa - time of cycle start in Unix Timestamp,

bbbbb - device number,

cccc - firmware version,

$\mathrm{dd}$ - amount of measurements of instantaneous value used

to calculate the RMS value,

ee - frequency of excitation current,

$\mathrm{f}$ - measuring method,

ggg - order number of a single measurement result,

hh.hhhh - value of a single measurement result.

\section{Model and image reconstruction}

The example of the flood embankment is given in Fig. 6. The examples of different inserted electrodes into the embankments were presented in Fig. 7. The measurement system with the EIT device, transfer data to the cloud computing and image reconstruction was presented in Fig. 8.

In examples reported below, several EIT numerical measurement models of the flood embankment were presented. The conductivity of searched objects is unknown. The embankment with 16 electrodes, simulated areas inside (geometrical mesh, original and reconstruction model) was presented in Fig. 9.

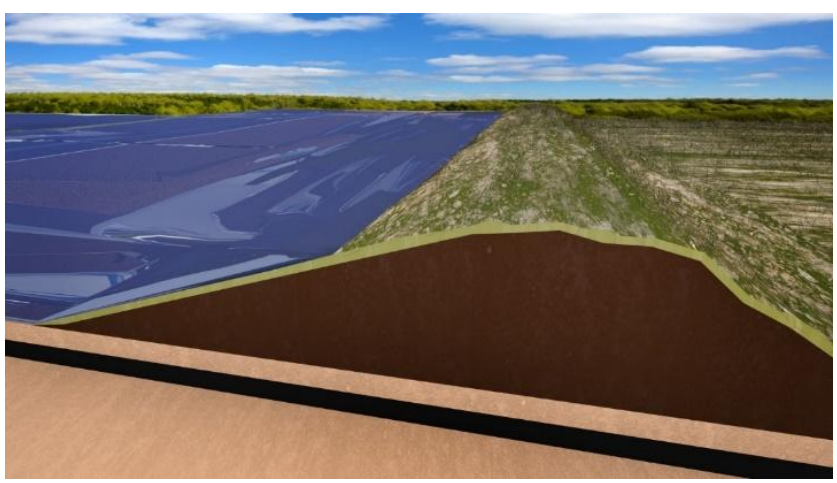

Fig. 6. The example of the flood embankment

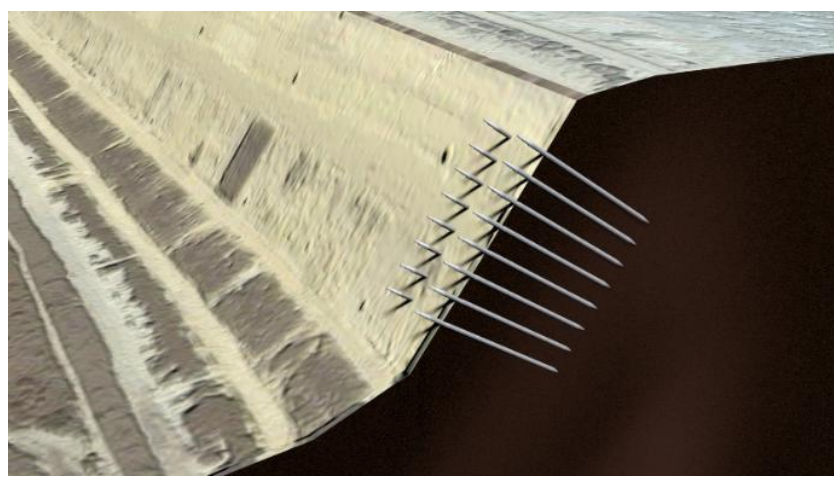

Fig. 7. The examples of electrodes

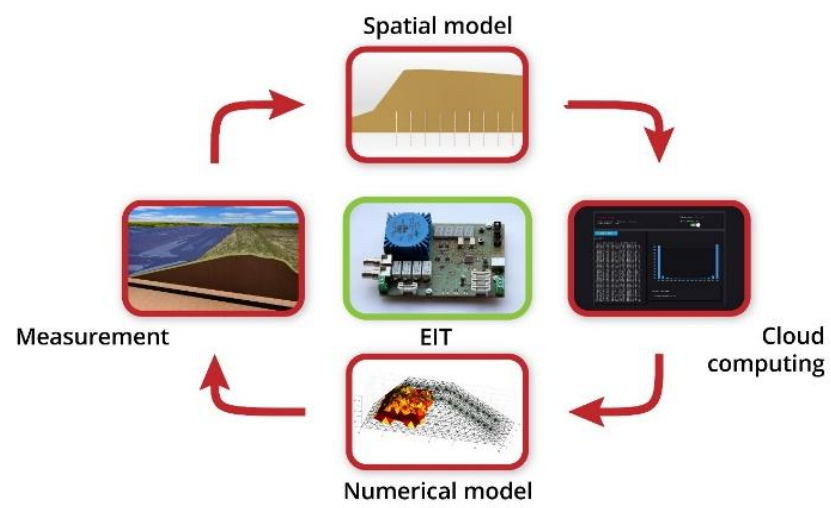

Fig. 8. The measurement system

a)

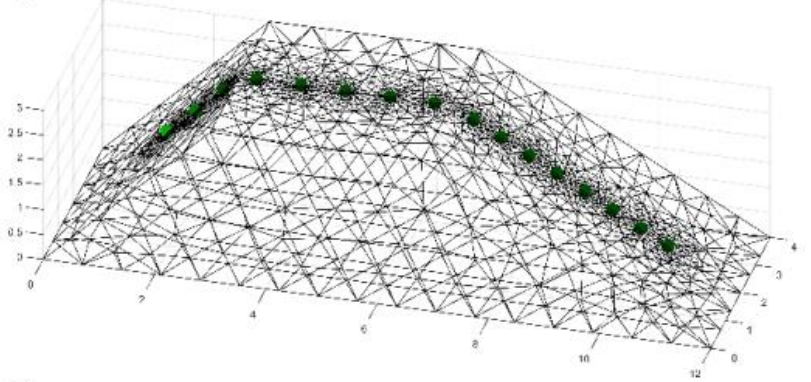

b)

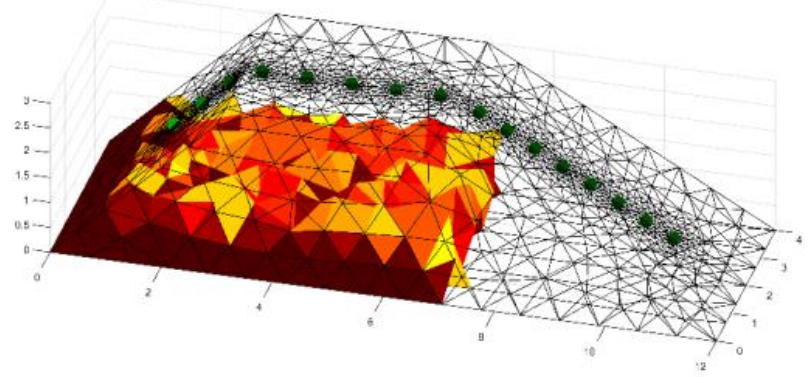

c)

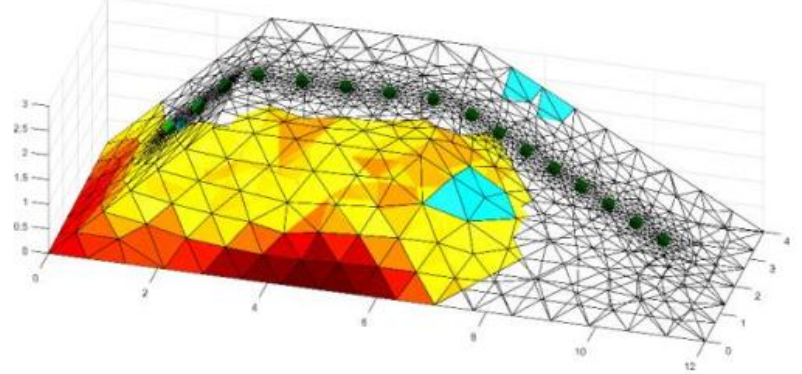

Fig. 9. The embankment: a) mesh model, b) model of object, c) Gauss-Newton with Laplace regularization 


\section{Conclusion}

This article presents the ERT system for tomographic measurements in the real environment. The presented solution was based on electrical resistance tomography. The design of the measuring system has been presented. Basic information about the constructed model system has been given. The concept of measuring equipment for data acquisition has been described. Electrical resistivity tomography was used to calculate the conductivity, which is based on the measurement of the potential difference.

\section{References}

[1] Jones G., Sentenac P., Zielinski M.: Desiccation cracking detection using 2-D and 3-D Electrical Resistivity Tomography: Validation on a flood embankment. Journal of Applied Geophysics 106/2014.

[2] Duda K., Adamkiewicz P., Rymarczyk T.: Nondestructive Method to Examine Brick Wall Dampness. International Interdisciplinary PhD Workshop 2016, 68-71.

[3] Filipowicz S.F, Rymarczyk T. Measurement Methods and Image Reconstruction in Electrical Impedance Tomography. Przeglad Elektrotechniczny 88(6)/2012, 247-250.

Ph.D. Eng. Tomasz Rymarczyk
e-mail: tomasz@rymarczyk.com

$\mathrm{He}$ is the director in Research and Development Center in Netrix S.A. and the director of the Institute of Computer Science and Innovative Technologies in the University of Economics and Innovation, Lublin, Poland.. He worked in many companies and institutes developing innovative projects and managing teams of employees. His research area focuses on the application of non-invasive imaging techniques, electrical tomography, image reconstruction, numerical modelling, image processing and analysis, process tomography, software engineering, knowledge engineering, artificial intelligence and computer measurement systems.

\section{M.Sc. Pawel Tchórzewski}

e-mail: pawel.tchorzewski@netrix.com.pl

$\mathrm{He}$ is a software developer in Research and Development Department in Netrix S.A. Currently, he is working on numerical methods in boundary value problems for partial differential equations and image reconstruction in electrical tomography. He graduated in physics at Maria Curie-Sklodowska University in Lublin.
[4] Kłosowski G., Kozłowski E., Gola A.: Integer linear programming in optimization of waste after cutting in the furniture manufacturing. Advances in Intelligent Systems and Computing 637/2018, 260-270.

[5] Kryszyn J., Smolik W.: Toolbox for 3D Modelling and Image Reconstruction in Electrical Capacitance Tomography. Automatyka, Pomiary w Gospodarce i Ochronie Środowiska 1/2017, 137-145.

[6] Polakowski K., Filipowicz S.F., Sikora J., Rymarczyk T.: Quality of imaging in multipath tomography. Przeglad Elektrotechniczny 85(12)/2009, 134-136.

[7] Polakowski K., Filipowicz S., Sikora J., Rymarczyk T.: Tomography Technology Application for Workflows of Gases Monitoring in The Automotive Systems, Przeglad Elektrotechniczny 84(12)/2008, 227-229.

[8] Rymarczyk T., Filipowicz S., Sikora J., Polakowski K.: A piecewise-constant minimal partition problem in the image reconstruction. Przegląd Elektrotechniczny 85(12)/2009, 141-143.

[9] Rymarczyk T., Sikora J., Waleska B.: Coupled Boundary Element Method and Level Set Function for Solving Inverse Problem in EIT. 7th World Congress on Industrial Process Tomography, WCIPT7 2013, 312-319.

[10] Smolik W.: Forward Problem Solver for Image Reconstruction by Nonlinear Optimization in Electrical Capacitance Tomography. Flow Measurement and Instrumentation 21/2010, 70-77.

[11] Soleimani M., Mitchell CN, Banasiak R., Wajman R., Adler A.: Fourdimensional electrical capacitance tomography imaging using experimental data. Progress In Electromagnetics Research 90/2009, 171-186.

[12] Wajman R., Banasiak R.: Tunnel-based method of sensitivity matrix calculation for 3D-ECT imaging. Sensor Review 34/2014, 273-283.

\section{Ph.D. Przemysław Adamkiewicz \\ e-mail: p.adamkiewicz@ netrix.com.pl}

He is a doctor of physics, graduate of Maria CurieSklodowska University in Lublin. He is a head of the R\&D Department at Netrix S.A. His research area focuses on electrical impedance tomography, electrical capacitance tomography, image reconstruction, forward problem, inverse problem, numerical modelling, image analysis and computer measurement systems.

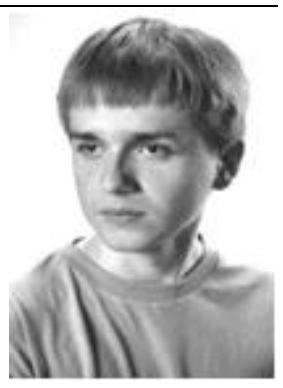

Prof. Jan Sikora

e-mail: sik59@wp.pl

He graduated from the Faculty of Electrical Engineering of the Warsaw University of Technology. During his 34 years of professional work, he has earned all grades, titles and positions at his home university, including the position of full professor. $\mathrm{He}$ has been associated since 1998 with the Institute of Electrical Engineering in Warsaw. In the years 20012004 , he worked as a senior research fellow at the University College London in the Group of Optical Tomography. S.R. Arridge. He was employed at the Faculty of Electrical Engineering and Computer Science. Actually, he works in the R\&D Department at Netrix S.A.

otrzymano/received: 10.07 .2018 przyjęto do druku/accepted: 15.09 .2018
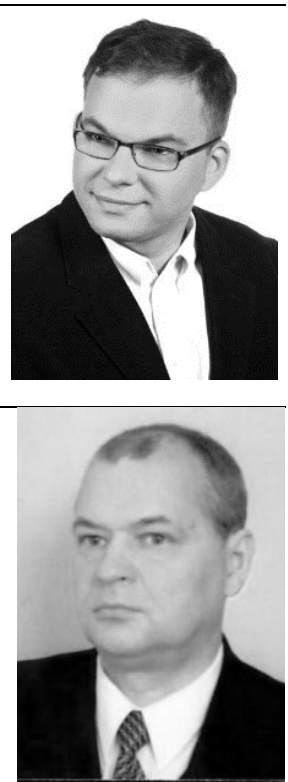